\title{
Lymph node dissection around left recurrent laryngeal nerve: robot-assisted vs. video-assisted McKeown esophagectomy for esophageal squamous cell carcinoma
}

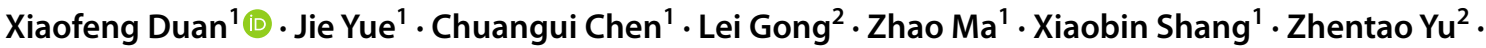 \\ Hongjing Jiang ${ }^{1}$
}

Received: 21 March 2020 / Accepted: 16 October 2020 / Published online: 26 October 2020

(c) Springer Science+Business Media, LLC, part of Springer Nature 2020

\begin{abstract}
Objective This study investigated the advantages of robot-assisted McKeown esophagectomy (RAME) for extensive superior mediastinal lymph node dissection (LND) versus video-assisted McKeown esophagectomy (VAME).

Methods The cases of 184 consecutive esophageal squamous cell carcinoma (ESCC) patients who underwent minimally invasive McKeown esophagectomy (109 with RAME, 75 with VAME) performed by a single surgical group between June 2017 and December 2019 were retrospectively reviewed.

Results Overall, 59.8\% (110/181) patients (70 treated with RAME, 40 treated with VAME; $64.2 \%$ vs. 53.3\%, respectively, $p=0.139$ ) underwent complete LND around the left recurrent laryngeal nerve (RLN) by pathological assessment. Cumulative sum plots showed increased numbers of LND around the left RLN (3.6 \pm 2.0 vs. $5.4 \pm 2.7, p=0.008)$ and a decreased incidence of recurrent nerve injury $(27.9 \%$ vs. $7.4 \%, p=0.037)$ after RAME learning curve. Despite similar overall LND results $(30.6 \pm 10.2$ vs. $28.1 \pm 10.2, p>0.05)$, RAME yielded more LND $(5.4 \pm 2.7$ vs. $4.4 \pm 2.2, p=0.016)$ and a greater proportion of lymph node metastases (37.0\% vs. 7.5\%) around the left RLN but induced a lower proportion of recurrent nerve injuries ( $7.4 \%$ vs. $22.5 \%, p=0.178)$ compared with VAME. Further analysis revealed that the complete LND around the left RLN was associated with recurrent nerve injury in the RAME $(20.0 \%$ vs. $5.1 \%, p=0.035)$ and VAME $(22.5 \%$ vs. $5.7 \%, p=0.041$ ) groups but did not affect other clinical outcomes including surgical duration, intraoperative blood loss, postoperative intensive care unit stay, hospital stay, and other complications.

Conclusions For patients with ESCC, RAME has great advantages in LND around the left RLN and recurrent nerve protection after learning curve of robotic esophagectomy.
\end{abstract}

Keywords Esophageal squamous cell carcinoma $\cdot$ Lymph node dissection $\cdot$ Minimally invasive esophagectomy $\cdot$ Recurrent laryngeal nerve $\cdot$ Robot surgery

Despite high postoperative complication and mortality rates after esophagectomy, radical surgical resection remains the mainstream treatment method for early esophageal

Hongjing Jiang

jianghj@vip.163.com

1 Department of Minimally Invasive Esophageal Surgery, Key Laboratory of Cancer Prevention and Therapy, National Clinical Research Center for Cancer, Tianjin Medical University Cancer Hospital and Institute, Tiyuanbei, Huanhuxi Rd., Hexi District, Tianjin 300060, China

2 Department of Esophageal Cancer, Tianjin Medical University Cancer Hospital and Institute, Tianjin 300060, China cancer and those after induction therapy. Minimally invasive esophagectomy (MIE) reportedly has better short-term clinical effects than open procedures, including a decreased incidence of postoperative complications, rapid postoperative recovery, and a shortened hospital stay [1-3]. Long-term follow-up results also confirm that MIE can achieve similar or better long-term survival than open surgery [4-7].

In recent years, robotic surgical systems have gradually been used to perform minimally invasive surgical treatment of esophageal cancer; similar to open surgical procedures, they can be divided into Ivor Lewis surgery and McKeown surgery. Kernstine et al. [8] first reported the use of robotassisted McKeown esophagectomy (RAME) in esophageal cancer. Park et al. [9] reported the experience of 114 patients 
with esophageal cancer treated with RAME and confirmed its safety and feasibility. Suda [10] and Park [11] confirmed that the robotic surgical system better visualizes the anatomy, enables lymph node dissection (LND) of the recurrent laryngeal nerve (RLN), and significantly reduces the incidence of recurrent nerve paralysis. Precise dissection and radical dissection of the bilateral recurrent laryngeal paralymphatic lymph nodes are particularly important for patients with esophageal squamous cell carcinoma (ESCC) [12].

At our center, a robotic surgical system installed in 2016 has been used for esophagectomy and radical LND for ESCC. In recent years, some studies have compared robot- and video-assisted MIE [13, 14] with open surgery $[15,16]$. The results confirmed that robot-assisted MIE can obtain better mediastinal LND and RLN protection [17, 18]. However, controversy persists without consensus. Here we reviewed our experience with robotic surgical procedures in patients with ESCC and investigated the advantages of RAME versus video-assisted McKeown esophagectomy (VAME) with a specific focus on the LND around the left RLN.

\section{Patients and methods}

\section{Patients}

To minimize selection bias, we retrospectively reviewed the data of ESCC patients who underwent MIE (RAME and VAME) performed by a single surgical group at our department between June 2017 and December 2019. During the study period, a total of 184 minimally invasive McKeown esophagectomies for ESCC were performed. We had no intended selection bias toward robotic or video surgical procedures; rather, we enrolled patients based on their consecutive admission. The present study was approved by our cancer center's institutional review board (no. E2019053). Written informed consent was obtained from each of the enrolled patients.

The preoperative evaluation of the study patients included medical history, physical examination, laboratory analysis, anesthesia evaluation, imaging examination, and endoscopy. Esophageal cancer diagnosis and staging were performed by endoscopic multi-point biopsy and endosonography. Ultrasonography and computed tomography combined with enhanced scanning determined the local growth, lymph node status, and distant metastasis. In some cases, positron emission tomography was used to exclude metastatic diseases and evaluate resectability. Patients who received induction chemo/chemoradiotherapy were also included. Chemotherapy consisted of platinum combined with paclitaxel, docetaxel, or fluorouracil. Radiotherapy with 46 Gy in 23 fractions for 5 days per week with weekly chemotherapy was used.

\section{Surgical procedures}

All patients underwent RAME or VAME with two-field lymphadenectomy performed by the surgical team of Dr. H.J.J. RAME were performed using a Da Vinci surgical system (Da Vinci $\mathrm{Si} / \mathrm{Xi}$, Intuitive Inc., USA). VAME was completed using a laparoscopic-thoracoscopic system. The surgical procedures included the following steps: transthoracic esophagectomy, LND, stomach mobilization, gastric tube construction, and left cervical esophagogastric anastomosis. The details for RAME are described below, and we used similar surgical procedures for VAME.

In the thoracic part, the patient was placed in the left lateral position and was ventilated by a single lumen endotracheal intubation. A 3-arm robotic surgical system (Da Vinci $\mathrm{Si}$ ) was used. The robotic port placed on the chest is shown in Fig. 1A. Insufflation with carbon dioxide to a pressure of $6-8 \mathrm{mmHg}$ was used to provide sufficient visualization. The patient's cart was docked onto the ports from behind the patient. After inspection, the esophagus was mobilized between the thoracic inlet and the diaphragmatic crura. The azygos vein was routinely transected, and lymph nodes were removed at the paratracheal, subcarinal, and paraesophageal areas, including both sides of the RLN (Fig. 1B). The patient was then placed in the supine position. First, the cervical esophagus was removed through a $5-\mathrm{cm}$ incision in the left side of the neck. Figure 1C shows the placements of ports for the abdomen. A pressure of $12-15 \mathrm{mmHg}$ was used. The robot was docked from the side of patient's head. We opened the gastrohepatic ligament, and separated and clipped the left gastric vessels. The lymph nodes surrounding the celiac trunk and the left gastric, common hepatic, and splenic arteries were dissected. The gastrocolic ligament and the short gastric vessels were transected after mobilizing of the stomach. We pulled out the stomach and specimen through a 5-cm midline incision and created a 3-cm-wide gastric tube. The gastrotomy line was closed with a linear stapler. A cervical anastomosis was constructed at the high point of the stomach using a circular stapler end to side (Fig. 1D). The distal end of the gastric tube was closed using a linear stapler approximately 1-2 cm away from the circular anastomosis. Nasogastric tubes, chest tubes, neck drains, and jejunostomy tubes were routinely inserted in all patients.

\section{Collection outcomes and analysis}

The baseline data, pathological outcomes, and lymph node yields were collected and analyzed. The number of dissected lymph nodes and positive lymph nodes were recorded according to the pathological reports. To examine further 

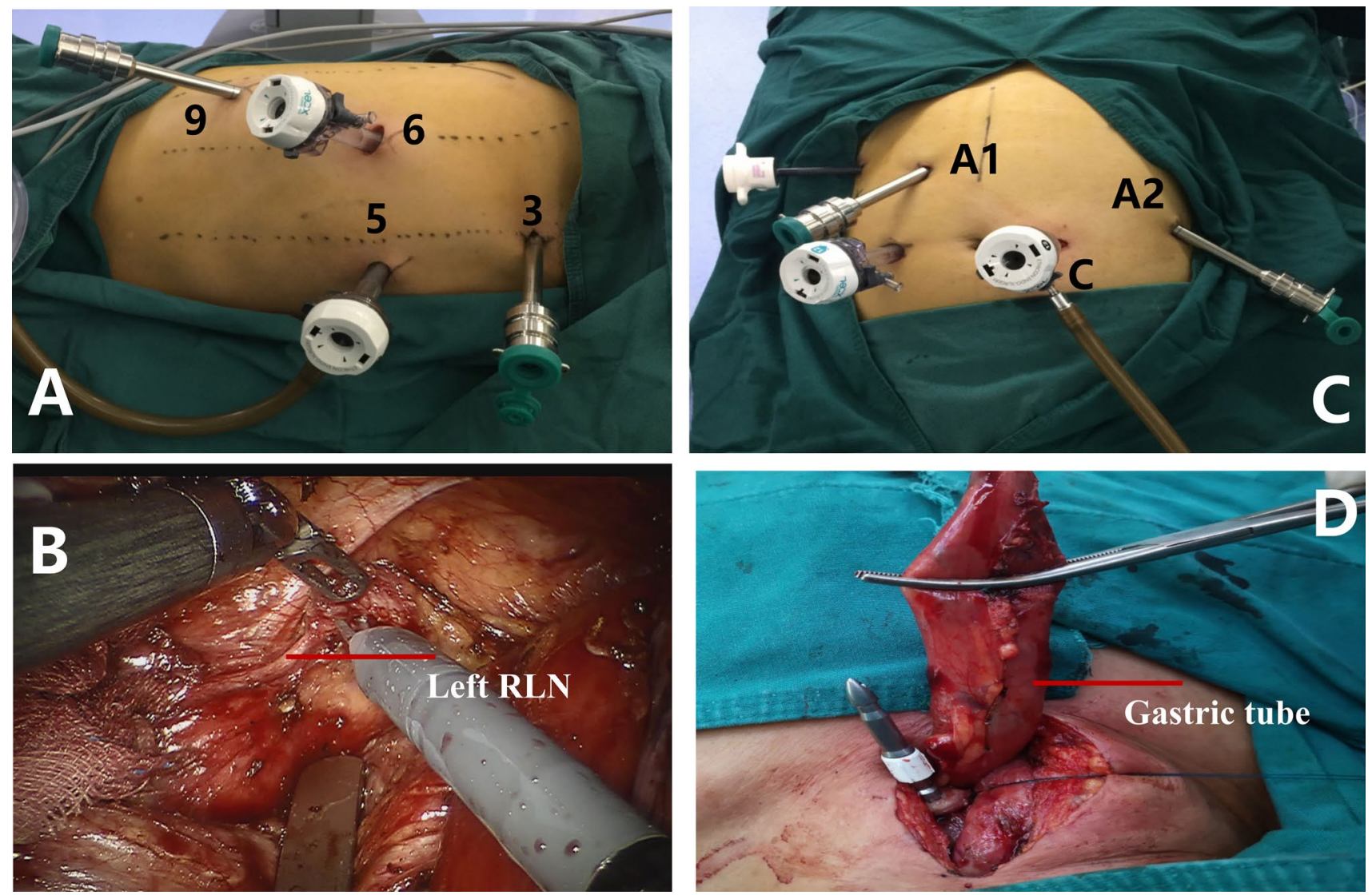

Fig. 1 A A 12-mm trocar for assistant was placed at the 5th-7th intercostal space (ICS) in the midaxillary line. A 12-mm trocar for camera at the 6th ICS in the posterior axillary line. Two 8-mm trocars for instruments were inserted as below: third ICS in the midaxillary line for arm 1, 9th ICS in the scapula angle line for arm. B The intraoperative imagines of robot-assisted esophagectomy in dissecting lymph nodes along left recurrent laryngeal nerve. C A 12-mm observational port was created just on the left side of umbilicus. A 12-mm and a

details, the dissected lymph nodes were classified into total categories as well as those along the right and left RLN. The complete LND around the left RLN meant that at least one lymph node was found by pathological examinations, but not the soft tissue. We also analyzed perioperative data including blood loss, surgical duration, postoperative hospital stay, major complications, and hospital mortality. The operation time is defined as time from incision until final closure. All major complications were evaluated based on the Esophagectomy Complications Consensus Group [19]. All patients were staged using the American Joint Committee on Cancer 8th edition Tumor Node Metastasis staging system [20].

\section{Statistical analysis}

Cumulative sum (CUSUM) plots were used to analyze the RAME learning curve. We calculated the CUSUM for each

5-mm trocar for assistant was placed at the right anterior axillary line below the costal arch and on the right side of umbilicus. Two 8-mm trocars for the instruments were inserted as below: robotic arm 1 was placed at the left anterior axillary line below the costal arch, robotic arm 2 was placed at the right midclavicular line, respectively. D The gastric tube of $3 \mathrm{~cm}$ wide was pulled up to the neck and a cervical anastomosis was constructed at the high point of the stomach using a circular stapler end to side

patient in chronologic order and visually inspected the plots for the LND number around left RLN. All data are shown as mean \pm SD or median (range) for continuous variables and as frequency (\%) for categorical variables. The unpaired Student's $t$-test or Wilcoxon rank sum test was used for continuous variables. The Chi-squared test or Fisher's exact test was used for categorical variables. Two-tailed $p$ values $<0.05$ were considered significant. The statistical analysis was performed using SPSS 24 (IBM SPSS Statistics for Windows version 24.0, USA).

\section{Results}

\section{Patient demographics}

The data of 184 ESCC patients (109 RAME, 75 VAME) underwent minimally invasive McKeown esophagectomy 
and two-field lymphadenectomy between June 2017 and December 2019 were collected and reviewed. Among them, the cases of RAME and VAME during the same study period are presented in Table 1. The demographic characteristics did not differ significantly between the two groups.

To reduce the impact of the surgical procedures in each group, 70 treated with RAME and 40 treated with VAME who underwent complete LND around the left RLN were included in the further analysis after postoperative pathological lymph node examination. To reduce the impact of the learning curve of robotic surgery, CUSUM plots showed that increased LND around the left RLN was seen after patient $43(3.6 \pm 2.0$ to $5.4 \pm 2.7, p=0.008)$, and the patients in the RAME group were separated into the early stage group (the first 43 patients) and late stage group (the last 27 patients),
Fig. 2. The demographic characteristics did not differ significantly among the VAME, first RAME, and last RAME groups (Table 1).

\section{Perioperative outcomes}

Before matching, the total number of LND $(24.8 \pm 8.0$ vs. $22.2 \pm 8.6, p=0.114)$ and number around the left RLNs $(2.8 \pm 2.6$ vs. $2.3 \pm 2.2, p=0.325)$ were similar in the RAME and VAME groups, respectively. The other perioperative outcomes were also similar between the two groups (Table 2). Matching by surgical procedures and learning curve revealed that RAME yielded more LND $(5.4 \pm 2.7$ vs. $4.4 \pm 2.2, p=0.016)$ and higher lymph node metastasis rates $(37.0 \%$ vs. $7.5 \%, p=0.003)$ around the left RLN

Table 1 Demographics characteristics

\begin{tabular}{|c|c|c|c|c|c|c|c|}
\hline \multirow[t]{2}{*}{ Variables } & \multicolumn{2}{|c|}{ All patients $(n=184, \%)$} & \multirow[t]{2}{*}{$p$-value } & \multicolumn{3}{|c|}{ LRLN lymph node dissection $(n=110, \%)$} & \multirow[t]{2}{*}{$p$-value } \\
\hline & $\operatorname{VAME}(n=75)$ & RAME $(n=109)$ & & VAME $(n=40)$ & Early RAME $(n=43)$ & Last RAME $(n=27)$ & \\
\hline Age, years, mean $\pm S D$ & $61.1 \pm 6.6$ & $60.0 \pm 6.1$ & 0.329 & $60 \pm 6.1$ & $59.6 \pm 6.8$ & $59.5 \pm 5$ & 0.845 \\
\hline Sex ratio (M:F) & $65: 10$ & $90: 19$ & 0.453 & $35: 5$ & $36: 7$ & $23: 4$ & 0.941 \\
\hline Smoking $(n, \%)$ & $48(64.0)$ & $72(66.1)$ & 0.774 & $27(67.5)$ & $28(65.1)$ & $20(74.1)$ & 0.758 \\
\hline Drinking $(n, \%)$ & $46(61.3)$ & $77(70.6)$ & 0.187 & $22(55.0)$ & $29(67.4)$ & $21(77.8)$ & 0.148 \\
\hline \multicolumn{8}{|l|}{ Comorbidity } \\
\hline Hypertension & $18(24.0)$ & $42(38.5)$ & 0.039 & $9(22.5)$ & $15(34.1)$ & $11(40.7)$ & 0.259 \\
\hline Diabetes & $6(8.0)$ & $10(9.2)$ & 0.781 & $4(10.0)$ & $5(11.6)$ & $3(10.9)$ & 1.000 \\
\hline Heart disease & $5(6.7)$ & $13(11.9)$ & 0.238 & $1(2.5)$ & 5 (11.6) & $3(11.1)$ & 0.266 \\
\hline Weight loss & & & 0.958 & & & & 0.290 \\
\hline Yes & $20(23.5)$ & $26(23.9)$ & & $10(25.0)$ & $15(34.9)$ & $5(18.5)$ & \\
\hline No & $65(76.5)$ & $83(76.1)$ & & $30(75.0)$ & $28(65.1)$ & $22(81.5)$ & \\
\hline Tumor location & & & 0.481 & & & & 0.817 \\
\hline $20-25 \mathrm{~cm}$ & $7(9.3)$ & $8(7.3)$ & & $3(7.5)$ & $2(4.7)$ & $2(7.4)$ & \\
\hline$>25 \& \leq 30 \mathrm{~cm}$ & $29(38.7)$ & $35(32.1)$ & & $12(30.0)$ & $14(32.6)$ & $10(37.0)$ & \\
\hline$>30 \mathrm{~cm}$ & $36(48.0)$ & $64(58.7)$ & & $23(57.5)$ & $27(62.8)$ & $14(51.9)$ & \\
\hline Mutitumor & $3(4.0)$ & $2(1.8)$ & & $2(5.0)$ & $0(0)$ & $1(3.7)$ & \\
\hline $\begin{array}{l}\text { Neoadjuvant chemo- } \\
\text { radiotherapy/chemo- } \\
\text { therapy }\end{array}$ & $10 / 10$ & $12 / 16$ & 0.877 & $2 / 9$ & $6 / 8$ & $2 / 4$ & 0.653 \\
\hline $\mathrm{pCR}$ & $4(20)$ & $7(25)$ & - & $2(18.2)$ & $5(35.7)$ & $0(0)$ & - \\
\hline Pathological T stage & & & 0.213 & & & & 0.514 \\
\hline 0 & $4(5.3)$ & $8(7.3)$ & & $2(5.1)$ & 5 (11.6) & $1(3.7)$ & \\
\hline 1 & $23(30.7)$ & $18(16.5)$ & & $8(20.5)$ & $10(23.3)$ & $4(14.8)$ & \\
\hline 2 & $14(18.7)$ & $26(23.9)$ & & $11(28.2)$ & $9(20.9)$ & $4(14.8)$ & \\
\hline 3 & $23(30.7)$ & $34(31.2)$ & & $12(30.8)$ & $9(20.9)$ & $8(29.6)$ & \\
\hline 4 & $11(14.7)$ & $23(21.1)$ & & $6(15.4)$ & $10(23.3)$ & $10(37.0)$ & \\
\hline Pathological N stage & & & 0.327 & & & & 0.113 \\
\hline 0 & $45(60.0)$ & $52(47.7)$ & & $20(50.0)$ & $25(58.1)$ & $8(29.6)$ & \\
\hline 1 & $15(20.0)$ & $29(26.6)$ & & $10(25.0)$ & $12(27.9)$ & $8(29.6)$ & \\
\hline 2 & $13(17.3)$ & $21(19.3)$ & & $9(22.5)$ & $5(11.6)$ & $7(25.9)$ & \\
\hline 3 & $2(2.7)$ & $7(6.4)$ & & $1(2.5)$ & $1(2.3)$ & $4(14.8)$ & \\
\hline
\end{tabular}

$L R L N$ left recurrent laryngeal nerve 
Fig. 2 Study flow chart and central findings

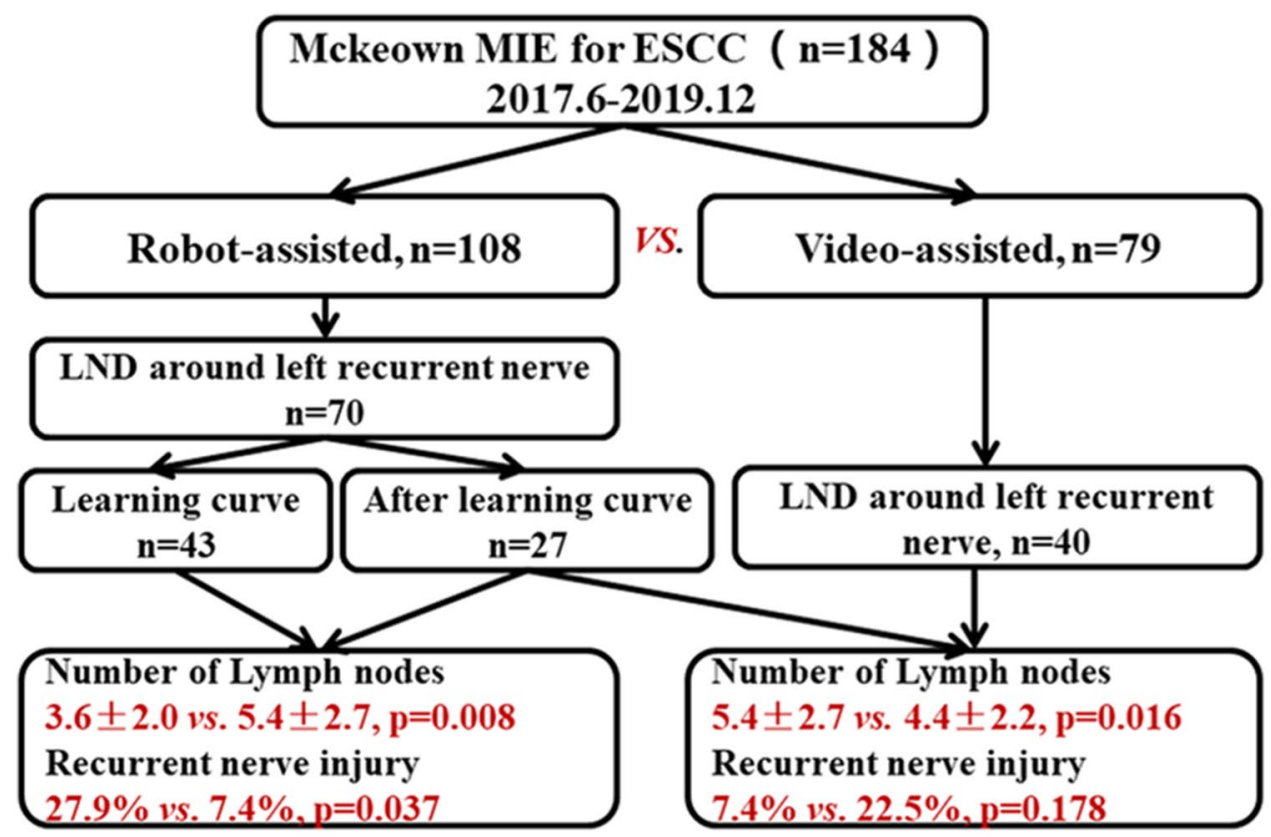

Table 2 Perioperative outcomes

\begin{tabular}{|c|c|c|c|c|c|c|c|}
\hline \multirow[t]{2}{*}{ Variables } & \multicolumn{2}{|c|}{ All patients $(n=184, \%)$} & \multirow[t]{2}{*}{$p$-value } & \multicolumn{3}{|c|}{ LRLN lymph node dissection $(n=110, \%)$} & \multirow[t]{2}{*}{$p$-value* } \\
\hline & $\operatorname{VAME}(n=75)$ & $\operatorname{RAME}(n=109)$ & & $\operatorname{VAME}(n=40)$ & Early RAME $(n=43)$ & Last RAME $(n=27)$ & \\
\hline Operation time & $321.8 \pm 29.1$ & $321.2 \pm 45.0$ & 0.336 & $321.9 \pm 35.1$ & $327.4 \pm 37.5$ & $324.5 \pm 50.5$ & 0.827 \\
\hline Blood loss & $187.7 \pm 27.8$ & $198.1 \pm 35.2$ & 0.379 & $188.1 \pm 29.2$ & $200.0 \pm 4.6$ & $171.2 \pm 47.6$ & 0.003 \\
\hline Re-surgery & 0 & 0 & & 0 & 0 & 0 & \\
\hline $\mathrm{R} 0$ resection & $74(98.7)$ & $109(100)$ & 0.408 & $40(100)$ & $43(100)$ & $27(100)$ & 1.000 \\
\hline Number of DLN & $22.2 \pm 8.6$ & $24.8 \pm 8.0$ & 0.114 & $28.1 \pm 10.2$ & $23.2 \pm 5.9$ & $30.6 \pm 10.2$ & 0.003 \\
\hline RRLN lymph node & $2.2 \pm 1.5$ & $2.7 \pm 1.7$ & 0.242 & $2.5 \pm 1.7$ & $2.7 \pm 1.4$ & $2.8 \pm 1.6$ & 0.785 \\
\hline Metastasis rate & $7(9.3)$ & $16(14.7)$ & 0.281 & $5(12.5)$ & $5(11.6)$ & $11(40.7)$ & 0.004 \\
\hline LRLN lymph node & $2.3 \pm 2.2$ & $2.8 \pm 2.6$ & 0.325 & $4.4 \pm 2.2$ & $3.6 \pm 2.0$ & $5.4 \pm 2.7$ & 0.008 \\
\hline Metastasis rate & $3(4.0)$ & $15(13.8)$ & 0.029 & $3(7.5)$ & $5(11.6)$ & $10(37.0)$ & 0.006 \\
\hline 90-day mortality & 0 & 0 & - & 0 & 0 & 0 & - \\
\hline ICU stay, $n$ & $8(10.7)$ & $8(7.3)$ & 0.431 & $6(15.0)$ & $3(7.0)$ & $2(7.4)$ & 0.476 \\
\hline Length of ICU stay & $7(3-20)$ & $5.5(1-21)$ & 0.495 & $7(3-20)$ & $4,5,21$ & 6,10 & 0.895 \\
\hline Postoperative stay & $18.9 \pm 7.8$ & $18.0 \pm 5.9$ & 0.596 & $17.8 \pm 6.5$ & $16.3 \pm 3.5$ & $20.1 \pm 8.3$ & 0.056 \\
\hline
\end{tabular}

$R R L N$ right recurrent laryngeal nerve, $D L N$ dissected lymph node, $L R L N$ left recurrent laryngeal nerve

${ }^{*} p$ value of difference between early and late RAME group

than VAME. In addition, the last RAME group included more total LND number than the early RAME group over the learning curve $(30.6 \pm 10.2$ vs. $23.2 \pm 5.9, p=0.003)$ despite being similar with the VAME group $(30.6 \pm 10.2$ vs. $28.1 \pm 10.2, p=0.105)$. Similar to the entire study population, the mean number of LND around the right RLN in the RAME group was the same as that in the VAME group $(2.8 \pm 1.6$ vs. $2.5 \pm 1.7, p=0.785)$.

\section{Postoperative complications}

The overall rates of postoperative complications were similar in the two matched cohorts $(40.7 \%$ vs. $35.0 \%, p=0.862$; Table 3). Specifically, the rate of pneumonia and incidence of anastomotic leakage were not significantly different between groups. Focusing on recurrent nerve injury, the incidence decreased significantly from $27.9 \%$ in the early RAME group to $7.4 \%$ in the last RAME group $(p=0.037)$. 
Table 3 Postoperative complications

\begin{tabular}{|c|c|c|c|c|c|c|c|}
\hline \multirow[t]{2}{*}{ Variables } & \multicolumn{2}{|c|}{ All patients $(n=184, \%)$} & \multirow[t]{2}{*}{$p$-value } & \multicolumn{3}{|c|}{ LRLN lymph node dissection $(n=110, \%)$} & \multirow[t]{2}{*}{$p$-value } \\
\hline & $\operatorname{VAME}(n=75)$ & RAME $(n=109)$ & & $\operatorname{VAME}(n=40)$ & $\begin{array}{l}\text { Early } \\
\text { RAME } \\
(n=43)\end{array}$ & Last RAME $(n=27)$ & \\
\hline Overall complications & $20(26.7)$ & $36(33.0)$ & 0.357 & $14(35.0)$ & $15(34.9)$ & $11(40.7)$ & 0.862 \\
\hline RLN paralysis & $11(14.7)$ & $16(14.7)$ & 0.998 & $9(22.5)$ & $12(27.9)$ & $2(7.4)$ & $0.106^{*}$ \\
\hline Pulmonary infection & $9(12.0)$ & $7(6.4)$ & 0.187 & $7(17.5)$ & $4(9.3)$ & $1(3.7)$ & 0.225 \\
\hline Ventilator-assisted ventilation & $8(10.7)$ & $8(7.3)$ & 0.431 & $6(15.0)$ & $3(7.0)$ & $2(7.0)$ & 0.476 \\
\hline Anastomotic leakages & $4(5.3)$ & $6(5.5)$ & 1.000 & $1(2.5)$ & $1(2.3)$ & $3(11.1)$ & 0.295 \\
\hline Tracheoesophageal fistula & $0(0)$ & $3(2.8)$ & 0.272 & $0(0)$ & $0(0)$ & $1(3.7)$ & 0.245 \\
\hline Pleural effusion & $0(0)$ & $3(2.8)$ & 0.272 & $0(0)$ & $0(0)$ & $1(3.7)$ & 0.245 \\
\hline Atelectasis & $2(2.7)$ & $1(0.9)$ & 0.568 & $2(5.0)$ & $0(0)$ & $1(3.7)$ & 0.349 \\
\hline Surgical site infections & $0(0)$ & $2(1.8)$ & 0.514 & $0(0)$ & $0(0)$ & $1(3.7)$ & 0.245 \\
\hline Chylothorax & $1(1.3)$ & $1(0.9)$ & 1.000 & $1(2.5)$ & $0(0)$ & $1(3.7)$ & 0.519 \\
\hline Arrhythmia & $0(0)$ & $2(1.8)$ & 0.514 & $0(0)$ & $1(2.3)$ & $0(0)$ & 1.000 \\
\hline Stroke & $0(0)$ & $1(0.9)$ & 1.000 & 0 & 0 & 0 & - \\
\hline ARF & $0(0)$ & $1(0.9)$ & 1.000 & $0(0)$ & $0(0)$ & $1(3.7)$ & 0.245 \\
\hline Chest infection & $0(0)$ & $1(0.9)$ & 1.000 & $0(0)$ & $0(0)$ & $1(3.7)$ & 0.245 \\
\hline
\end{tabular}

$L R L N$ left recurrent laryngeal nerve, $A R F$ acute renal failure

${ }^{*} p=0.037$ between early and last RAME group

The incidence of recurrent nerve injury was still lower in the last RAME group than in the VAME group, although the difference was significant different $(7.4 \%$ vs. $22.5 \%, p=0.106)$.

\section{Effect of LND around left RLN on clinical outcomes}

We further investigated whether complete LND of left RLN would have an adverse effect on perioperative outcomes. The cases of complete LND around left RLN had greater numbers of total LND for both RAME ( $26.1 \pm 7.8$ vs. $22.0 \pm 7.9$, $p=0.070)$ and VAME $(28.1 \pm 10.2$ vs. $15.5 \pm 5.0, p<0.001)$ and more advanced $\mathrm{pN}$ stage (50\% vs. $28.6 \%, p=0.059$ ) for VAME but not RAME. The complete LND around left RLN was associated with recurrent nerve injury in the RAME $(20.0 \%$ vs. $5.1 \%, p=0.035)$ and VAME $(22.5 \%$ vs. $5.7 \%$, $p=0.041)$ groups but had no effect on other clinical outcomes including surgical duration, interoperative blood loss, postoperative intensive care unit or hospital stay, and other complications (Table 4).

\section{Discussion}

Theoretically, RAME achieves better short-term and oncological results than traditional MIE [21]. Using a magnified three-dimensional image, articulating forceps, and tremor filtering, RAME can overcome some limitations of traditional MIE. In addition, through enhanced visualization of tissue structures, robotic surgical systems can facilitate intraoperative steps, reduce injury to neighboring structures, and improve LND precision [22]. Third, the robotic system can accelerate the learning curve by compensating for the drawbacks of video-assisted esophagectomy when performed in the confined mediastinal space, retroperitoneal space, and splenic hilum [23]. More recently, roboticassisted surgery has been used in minimally invasive McKeown esophagectomy and demonstrated good short-term outcomes [16, 17, 24, 25].

In the present study, we compared the short-term outcomes of RAME versus VAME for the surgical treatment of patients with ESCC in a single surgical group and mainly focused on LND around the left RLN. By matching and performing CUSUM analysis, we found that RAME yielded a higher number of lymph nodes around the left RLN than VAME and provided better recurrent nerve protection after the learning curve of robotic esophagectomy in late stage group than early stage group. These data suggest that RAME is a safe and feasible technique with advantages over VAME.

Robotic esophageal surgery is among the most challenging procedures in thoracic surgery. With its popularity and widespread applicability, its learning curve requires evaluation. According to Hernandez [26], the surgical proficiency of robotic esophagectomy with Ivor Lewis can be obtained after approximately 20 cases are treated by surgeons skilled in non-robotic MIE. Sarkaria et al. [27] conducted a learning curve analysis of 100 robot-assisted MIE and noted that the median operative time decreased to approximately 370 min between the 30th and 45th cases. Zhang et al. [28] 
Table 4 Perioperative effect of lymph node dissection around left recurrent laryngeal nerve

\begin{tabular}{|c|c|c|c|c|c|c|}
\hline \multirow[t]{2}{*}{ Variables } & \multicolumn{2}{|c|}{$\operatorname{VAME}(n=75, \%)$} & \multirow[t]{2}{*}{$p$-value } & \multicolumn{2}{|c|}{ RAME $(n=109, \%)$} & \multirow[t]{2}{*}{$p$-value } \\
\hline & Yes $(n=40)$ & No $(n=35)$ & & Yes $(n=70)$ & No $(n=39)$ & \\
\hline Operation time & $321.9 \pm 35.1$ & $303.1 \pm 39.6$ & 0.114 & $326.3 \pm 42.5$ & $311.9 \pm 47.4$ & 0.211 \\
\hline Blood loss & $188.2 \pm 29.2$ & $212.5 \pm 26.3$ & 0.917 & $189.2 \pm 24.7$ & $214.8 \pm 76.3$ & 0.258 \\
\hline Number of DLN & $28.1 \pm 10.2$ & $15.5 \pm 5.0$ & $<0.001$ & $26.1 \pm 7.8$ & $22.0 \pm 7.9$ & 0.070 \\
\hline ICU stay, $n$ & $6(15.0)$ & $2(5.7)$ & 0.271 & $5(7.1)$ & $3(7.7)$ & 1.000 \\
\hline Length of ICU stay & $7(3-20)$ & 7,16 & - & $6(4-21)$ & $1,3,8$ & - \\
\hline Postoperative stay & $17.8 \pm 6.5$ & $20.2 \pm 9.2$ & 0.462 & $17.8 \pm 5.6$ & $18.5 \pm 6.4$ & 0.688 \\
\hline $\mathrm{pT}$ & & & 1.000 & & & 0.875 \\
\hline T0-2 & $22(55.0)$ & $19(54.3)$ & & $33(47.1)$ & $19(48.7)$ & \\
\hline T3-4 & $18(45.0)$ & $16(45.7)$ & & $37(52.9)$ & $20(51.3)$ & \\
\hline $\mathrm{pN}$ & & & 0.059 & & & 0.875 \\
\hline No & $20(50.0)$ & $25(71.4)$ & & $33(47.1)$ & $19(48.7)$ & \\
\hline $\mathrm{N} 1-3$ & $20(50.0)$ & $10(28.6)$ & & $37(52.9)$ & $20(51.3)$ & \\
\hline Overall complications & $14(35.0)$ & $6(17.1)$ & 0.081 & $26(37.1)$ & $10(25.6)$ & 0.289 \\
\hline Recurrent nerve injury & $9(22.5)$ & $2(5.7)$ & 0.041 & $14(20.0)$ & $2(5.1)$ & 0.035 \\
\hline Pulmonary infection & $7(17.5)$ & $2(5.7)$ & 0.162 & $5(7.1)$ & $2(5.1)$ & 1.000 \\
\hline Ventilator-assisted ventilation & $6(15.0)$ & $2(5.7)$ & 0.271 & $5(7.1)$ & $3(7.7)$ & 1.000 \\
\hline Anastomotic leakages & $1(2.5)$ & $3(8.6)$ & 0.334 & $4(5.7)$ & $2(2.6)$ & 0.653 \\
\hline Tracheoesophageal fistula & 0 & 0 & - & $1(1.4)$ & $2(5.1)$ & 0.291 \\
\hline Pleural effusion & 0 & 0 & - & $1(1.4)$ & $2(5.1)$ & 0.291 \\
\hline Atelectasis & $2(5.0)$ & 0 & 0.495 & $1(1.4)$ & 0 & 1.000 \\
\hline Surgical site infections & 0 & 0 & - & $1(1.4)$ & $1(2.6)$ & 1.000 \\
\hline Chylothorax & $1(2.5)$ & 0 & 1.000 & $1(1.4)$ & 0 & 1.000 \\
\hline Arrhythmia & 0 & 0 & - & $1(1.4)$ & $1(2.6)$ & 1.000 \\
\hline Stroke & 0 & 0 & - & 0 & $1(2.6)$ & 0.358 \\
\hline $\mathrm{ARF}$ & 0 & 0 & - & $1(1.4)$ & 0 & 1.000 \\
\hline Chest infection & 0 & 0 & - & $1(1.4)$ & 0 & 1.000 \\
\hline
\end{tabular}

$A R F$ acute renal failure, $D L N$ dissected lymph node retrospectively reviewed 72 consecutive patients treated with RAME and found that experience with 26 cases is required to gain early proficiency for a surgeon experienced with open and thoracolaparoscopic esophagectomy.

The LND around the left RLN in ESCC cases is a surgically challenging procedure. In the present study, we evaluated the learning curve of RAME in lymphadenectomy around the left RLN to enable better comparison with VAME. For a surgeon experienced with VAME, experience of 43 cases is required to gain proficiency with robotassisted lymphadenectomy around the left RLN, which is evidenced by more completed LND and a decreased recurrent nerve injury rate. In this respect, robot-assisted surgery shows great advantages. The feasibility and safety of robotassisted lymphadenectomy along the bilateral RLN were demonstrated in a previous study. Chao et al. [29] showed that, compared with VAME, RAME resulted in a higher LND around the left RLN without increasing morbidity. In a recent study of 271 patients in each group, the number of dissected lymph nodes along RLN was significantly higher using RAME than VAME [21]. We also found that the LND number of left RLN in present study was larger than those of previous studies $[11,30]$. With respect to total LDN, Park et al. [11] and Deng et al. [30] retrospectively found that robot-assisted esophagectomy yielded more dissected lymph nodes than conventional MIE. However, several recent studies together with our study demonstrated that the number of total dissected lymph nodes was comparable between the two surgical approaches [13, 21].

Recurrent nerve injury remains a concern for LND around RLN. Recurrent nerve injury was the most frequently observed complication in RAME and VAME in the present study as seen in previously published data. Park et al. [9] reported a $26.5 \%$ incidence of hoarseness after robotic esophageal surgery. Park et al. [12] again reported that recurrent nerve paralysis after robot-assisted MIE was significantly reduced from 36 to $17 \%$ after 60 cases. After the learning curve of 43 cases, the incidence of recurrent nerve injury decreased from 27.9 to $7.4 \%$ in the present study. This might be attributed to the better skeletonization of the RLN, the use of a lower-energy platform, and the use of more cold instruments in recent RAME. 
This study has some limitations including its retrospective nature with potential selection bias. Although the sample size of this study was relatively large, the number of patients that remained after matching was relatively small. In addition, we are still following our patients to determine their long-term outcomes. One recent study found that RAME was associated with a lower rate of mediastinal lymph nodes recurrence after median follow-up of 20.2 months [21]. More thorough LND, especially in the lymph nodes along RLNs, and more precise esophageal en-bloc resection with the periesophageal tissue may enable a better oncological outcome. Furthermore, we focused on only LND around the left RLN to determine the learning curve of robotic surgery for better comparison; thus, other parameters should be used for determining the learning curve in future studies. Neoadjuvant therapy has been recommended as the standard treatment approach for patients with esophageal cancer to improve long-term survival rates. The other limitation of the present study is that only a small number of patients received neoadjuvant therapy; however, the concept of neoadjuvant therapy is gradually gaining popularity.

Funding This work was supported by Basic Research Grant from Tianjin Municipal Education Commission (2018KJ070) and Excellence in Surgery Grant from Bethune Charitable Foundation (HZB-20181119-8).

\section{Compliance with ethical standards}

Disclosures Drs. Xiaofeng Duan, Jie Yue, Chuangui Chen, Lei Gong, Zhao Ma, Xiaobin Shang, Zhentao Yu and Hongjing Jiang have no conflicts of interest or financial ties to disclose.

\section{References}

1. Moon DH, Lee JM, Jeon JH, Yang HC, Kim MS (2017) Clinical outcomes of video-assisted thoracoscopic surgery esophagectomy for esophageal cancer: a propensity score-matched analysis. J Thorac Dis 9:3005-3012

2. Kauppila JH, Helminen O, Kyto V, Gunn J, Lagergren J, Sihvo E (2018) Short-term outcomes following minimally invasive and open esophagectomy: a population-based study from Finland and Sweden. Ann Surg Oncol 25:326-332

3. Takeuchi H, Miyata H, Ozawa S, Udagawa H, Osugi H, Matsubara $\mathrm{H}$ (2017) Comparison of short-term outcomes between open and minimally invasive esophagectomy for esophageal cancer using a nationwide database in Japan. Ann Surg Oncol 24:1821-1827

4. Yamashita K, Watanabe M, Mine S, Toihata T, Fukudome I, Okamura A (2018) Minimally invasive esophagectomy attenuates the postoperative inflammatory response and improves survival compared with open esophagectomy in patients with esophageal cancer: a propensity score matched analysis. Surg Endosc. https ://doi.org/10.1007/s00464-018-6187-z

5. Mitzman B, Lutfi W, Wang CH, Krantz S, Howington JA, Kim KW (2017) Minimally invasive esophagectomy provides equivalent survival to open esophagectomy: an analysis of the national cancer database. Semin Thorac Cardiovasc Surg 29:244-253

6. Weksler B, Sullivan JL (2017) Survival after esophagectomy: a propensity-matched study of different surgical approaches. Ann Thorac Surg 104:1138-1146

7. Straatman J, van der Wielen N, Cuesta MA, Daams F, Roig Garcia J (2017) Minimally invasive versus open esophageal resection: three-year follow-up of the previously reported randomized controlled trial: the TIME trial. Ann Surg 266:232-236

8. Kernstine KH, DeArmond DT, Karimi M, Van Natta TL, Campos JH, Campos JC (2004) The robotic, 2-stage, 3-field esophagolymphadenectomy. J Thorac Cardiovasc Surg 127:1847-1849

9. Park SY, Kim DJ, Yu WS, Jung HS (2016) Robot-assisted thoracoscopic esophagectomy with extensive mediastinal lymphadenectomy: experience with 114 consecutive patients with intrathoracic esophageal cancer. Dis Esophagus 29:326-332

10. Suda K, Ishida Y, Kawamura Y, Inaba K, Kanaya S, Teramukai S (2012) Robot-assisted thoracoscopic lymphadenectomy along the left recurrent laryngeal nerve for esophageal squamous cell carcinoma in the prone position: technical report and short-term outcomes. World J Surg 36:1608-1616

11. Park S, Hwang Y, Lee HJ, Park IK, Kim YT, Kang CH (2016) Comparison of robot-assisted esophagectomy and thoracoscopic esophagectomy in esophageal squamous cell carcinoma. J Thorac Dis 8:2853-2861

12. Park S, Hyun K, Lee HJ, Park IK, Kim YT, Kang CH (2018) A study of the learning curve for robotic oesophagectomy for oesophageal cancer. Eur J Cardiothorac Surg 53:862-870

13. Chen J, Liu Q, Zhang X (2019) Comparisons of short-term outcomes between robot-assisted and thoraco-laparoscopic esophagectomy with extended two-field lymph node dissection for resectable thoracic esophageal squamous cell carcinoma. J Thorac Dis 11:3874-3880

14. Zhang Y, Han Y, Gan Q, Yang H, Tan Z, Lin Y (2019) Early outcomes of robot-assisted versus thoracoscopic-assisted Ivor Lewis esophagectomy for esophageal cancer: a propensity score-matched study. Ann Surg Oncol 26:1284-1291

15. Yun JK, Chong BK, Kim HJ, Lee IS, Gong CS, Kim BS, Lee GD, Choi S, Kim HR, Kim DK, Park SI, Kim YH (2019) Comparative outcomes of robot-assisted minimally invasive versus open esophagectomy in patients with esophageal squamous cell carcinoma: a propensity score-weighted analysis. Dis Esophagus. https ://doi.org/10.1093/dote/doz071

16. van der Sluis PC, van der Horst S, May AM, Schippers C, Brosens LAA, Joore HCA (2019) Robot-assisted minimally invasive thoracolaparoscopic esophagectomy versus open transthoracic esophagectomy for resectable esophageal cancer: a randomized controlled trial. Ann Surg 269:621-630

17. van der Horst $\mathrm{S}$, de Maat MFG, van der Sluis PC, Ruurda JP, van Hillegersberg R (2019) Extended thoracic lymph node dissection in robotic-assisted minimal invasive esophagectomy (RAMIE) for patients with superior mediastinal lymph node metastasis. Ann Cardiothorac Surg 8:218-225

18. Motoyama S, Sato Y, Wakita A, Kawakita Y, Nagaki Y, Imai K (2019) Extensive lymph node dissection around the left laryngeal nerve achieved with robot-assisted thoracoscopic esophagectomy. Anticancer Res 39:1337-1342

19. Low DE, Alderson D, Cecconello I, Chang AC, Darling GE, D'Journo XB (2015) International consensus on standardization of data collection for complications associated with esophagectomy: Esophagectomy Complications Consensus Group (ECCG). Ann Surg 262:286-294

20. Rice TW, Ishwaran H, Hofstetter WL, Kelsen DP, Apperson-Hansen C, Blackstone EH (2016) Recommendations for pathologic staging (pTNM) of cancer of the esophagus and 
esophagogastric junction for the 8th edition AJCC/UICC staging. Dis Esophagus 29:897-905

21. Yang X, Zhang B, Li R, Hua Y, Yang Y, He B, He Y, Ye B, Guo X, Sun Y, Li Z (2019) Short- and mid-term outcomes of robotic versus thoraco-laparoscopic McKeown esophagectomy for squamous cell esophageal cancer: a propensity score-matched study. Dis Esophagus. https://doi.org/10.1093/dote/doz080

22. Ruurda JP, van der Sluis PC, van der Horst S, van Hilllegersberg R (2015) Robot-assisted minimally invasive esophagectomy for esophageal cancer: a systematic review. J Surg Oncol 112:257-265

23. Kernstine KH (2008) The first series of completely robotic esophagectomies with three-field lymphadenectomy: initial experience. Surg Endosc 22:2102

24. van der Sluis PC, Ruurda JP, Verhage RJ, van der Horst S, Haverkamp L, Siersema PD (2015) Oncologic long-term results of robot-assisted minimally invasive thoraco-laparoscopic esophagectomy with two-field lymphadenectomy for esophageal cancer. Ann Surg Oncol 22(Suppl 3):S1350-S1356

25. Puntambekar S, Kenawadekar R, Kumar S, Joshi S, Agarwal G, Reddy S (2015) Robotic transthoracic esophagectomy. BMC Surg 15:47

26. Hernandez JM, Dimou F, Weber J, Almhanna K, Hoffe S, Shridhar R (2013) Defining the learning curve for robotic-assisted esophagogastrectomy. J Gastrointest Surg 17:1346-1351
27. Sarkaria IS, Rizk NP, Grosser R, Goldman D, Finley DJ, Ghanie A (2016) Attaining proficiency in robotic-assisted minimally invasive esophagectomy while maximizing safety during procedure development. Innovations (Phila) 11:268-273

28. Zhang H, Chen L, Wang Z, Zheng Y, Geng Y, Wang F (2018) The learning curve for robotic McKeown esophagectomy in patients with esophageal cancer. Ann Thorac Surg 105:1024-1030

29. Chao YK, Hsieh MJ, Liu YH, Liu HP (2018) Lymph node evaluation in robot-assisted versus video-assisted thoracoscopic esophagectomy for esophageal squamous cell carcinoma: apropensity-matched analysis. World J Surg 42:590-598

30. Deng HY, Huang WX, Li G, Li SX, Luo J, Alai G, Wang Y, Liu LX, Lin YD (2019) Comparison of short-term outcomes between robot-assisted minimally invasive esophagectomy and video-assisted minimally invasive esophagectomy in treating middle thoracic esophageal cancer. Dis Esophagus. https://doi. org/10.1093/dote/doy012

Publisher's Note Springer Nature remains neutral with regard to jurisdictional claims in published maps and institutional affiliations. 